\title{
Dimensionamento e Comparação de Estações de Tratamento de Efluentes Utilizando Lodos Ativados e Reator UASB para uma Cervejaria Artesanal
}

\author{
Carolina M. Rocha, Karina S. C. Machado, Laura H. de Andrade \\ \& Emanuel M. F. Brandt
}

\begin{abstract}
Instalações que produzem cervejas artesanais geram efluentes líquidos de elevadas cargas orgânicas, esses que apresenta potencial poluidor significativo, necessitando assim tratamento adequado para o descarte, tanto em corpos d'água como em redes de saneamento. Desta maneira, neste presente trabalho, estudou-se a possibilidade de implantação de um sistema de tratamento biológico para uma cervejaria, com sede na cidade de Belo Horizonte, apresentando duas propostas: Sistemas de Lodos Ativados e Reator UASB. Foram utilizadas amostras de efluente gerado na indústria estudada, onde se pode observar uma concentração de DBO no valor de $4.117 \mathrm{mg} / \mathrm{L}$ e de SS na ordem de $5.487 \mathrm{mg} / \mathrm{l}$. Dimensionou-se unidades contendo sistema de Lodos Ativados, apresentando $90 \%$ de eficiência de remoção de matéria orgânica, e duas unidades contendo UASB, a primeira seguida de um filtro biológico percolador ( $81 \%$ de eficiência de remoção de matéria orgânica) e a segunda seguida do sistema de Lodos Ativados ( $97 \%$ de eficiência de remoção de matéria orgânica). A qualidade do efluente final para as metodologias adotadas atendeu aos critérios de descarte da rede coletora da cidade.
\end{abstract}

\section{Palavras Chave: Tratamento biológico; Lodos Ativados Convencional; UASB.}

Installations that produce craft beers generate liquid effluents with high organic loads, which presents significant pollutant potential and treatment methods should be present for suitability for disposal, both in water bodies and in sanitation. Thus, in this paper, it was studied the possibility of developing a biological treatment system for a brewery, installed in the city of Belo Horizonte, with two proposals: activated sludge systems and UASB. Samples of the effluent generated in the study industry were collected and analyzed, and a concentration of BOD of $4,177 \mathrm{mg} / \mathrm{L}$ and of SS $5,487 \mathrm{mg} / \mathrm{L}$ were found. Units with an activated sludge system were designed, presenting $90 \%$ efficiency of removal of organic matter, and two units containing UASB, the first followed by a percolator biological filter ( $81 \%$ efficiency of removal of organic matter) and the second followed by the Activated Sludge system ( $97 \%$ efficiency of removal of organic matter). The final quality of the effluent for the methodologies used meet the effluent discharge criteria in the sanitation network.

Keywords: Biological Treatment; Conventional Activated Sludge; UASB Reactor. 


\section{Introdução}

Nos processos industriais, o uso da água, seja na incorporação ao produto, nas lavagens de máquinas e instalações, é bastante elevado, como consequência geramse efluentes contendo compostos orgânicos e inorgânicos que, muitas vezes, possuem elevado potencial poluidor. Como um setor de destaque em relação a essa questão encontram-se as indústrias de bebidas, como as cervejas, responsáveis pela produção de um efluente com elevada carga orgânica e alta concentração de sólidos em suspensão.

A água é ainda um dos principais componentes da cerveja, correspondendo à aproximadamente $90 \%$ da composição do produto e estima-se que para cada metro cubico de cerveja produzida, utiliza-se de 2 a $10 \mathrm{~m} 3$ de água5. Além de ser usada como matéria-prima, a água também está presente em diversas etapas como limpeza, operações de fermentação e pasteurização. Por conta disto, é grande a vazão de efluentes gerados, fazendo-se assim com que seja necessário o uso de métodos capazes de tratar este efluente de maneira eficiente, visando sua adequação para posterior descarte na rede de saneamento da cidade ou em corpos d'água.

Dessa forma, este trabalho consiste no dimensionamento de uma estação de tratamento de efluente para uma indústria de cerveja artesanal, uma vez que o atual tratamento não vem se mostrando eficiente no atendimento dos parâmetros exigidos para o lançamento à rede da COPASA, onde o efluente é descartado, acarretando em diversos problemas, tanto fiscais como institucionais de imagem empresarial.

\section{Metodologia}

O presente trabalho foi desenvolvido a partir de dados que foram coletados em uma cervejaria artesanal. As etapas foram divididas conforme apresentado na sequência:

- Caracterização do processo de geração e descarte do efluente a partir de visita técnica;

- Caracterização do efluente (Os parâmetros analisados na entrada e saída da ETE foram: Demanda Bioquímica de Oxigênio (DBO) [mg O2/L]; Demanda Química de Oxigênio (DQO) [mg
O2/L]; DQO Dissolvido [mg O2/L]; Nitrogênio Amoniacal [mgN_NH3/L]; Serie de Sólidos [mg $\mathrm{S} / \mathrm{L}])$;

- Proposição de alternativas para tratamento do efluente gerado;

- Comparação das alternativas dimensionadas.

\section{Resultados e Discussão}

Visando a caracterização do efluente gerado durante o processo de fabricação de cervejas artesanais, amostras do mesmo foram coletadas para realização de análises quantitativas em um laboratório especializado. Após os resultados obtidos pode-se observar que as concentrações de DQO (Demanda Química de Oxigênio), DBO (Demanda Bioquímica de Oxigênio) e SST (Sólidos Suspensos Voláteis) na saída da atual ETE são maiores do que valores encontrados para a entrada, o que indica a possibilidade de que a quantidade de efluente químico, esteja elevada em relação ao efluente biológico, oriundo do processo produtivo, ao ponto de interferir no tratamento atual, comprometendo a qualidade do efluente que vem sendo descartada.

As concentrações de DQO e SST, $12.400 \mathrm{mg} / \mathrm{L}$ e $2657 \mathrm{mg} / \mathrm{L}$, são superiores aos valores imposto para o não acréscimo na cobrança referente ao descarte do efluente na rede coletora, de $450 \mathrm{mg} / \mathrm{L}$ e $300 \mathrm{mg} / \mathrm{L}$, respectivamente.

De posse das informações relacionadas ao efluente gerado na cervejaria, foram propostas alternativas de tratamento com o intuito de atender às normas exigidas para o descarte do mesmo. O dimensionamento englobou alternativas utilizando Lodos Ativados Convencional e reator UASB. Decidiu-se pela utilização desses métodos, por serem sistemas amplamente utilizados no tratamento de efluentes com as mesmas características do efluente gerado na cervejaria em questão.

Os dimensionamentos das alternativas foram realizados com base nas metodologias de cálculos apresentadas por VON SPERLING (2002), CHERNICHARO (2010), ANDREOLI et al (2001) e a NBR 12.209, de maneira a atender os requisitos estipulados pela Norma Técnica 
187/5 (COPASA, 2014). A comparação das alternativas neste trabalho se desenvolveu através dos indicadores de eficiência para atingir as características desejadas para descarte do efluente, essa comparação é apresentada abaixo na tabela 1 .

Tabela 1. Inserir título Concentrações esperadas do efluente após tratamento

\begin{tabular}{|l|c|c|c|}
\hline Alternativa & $\begin{array}{c}\text { DBO } \\
(\mathrm{mg} / \mathrm{L})\end{array}$ & $\begin{array}{c}\text { DQO } \\
(\mathrm{mg} / \mathrm{L})\end{array}$ & $\begin{array}{c}\text { SST } \\
(\mathrm{mg} / \mathrm{L})\end{array}$ \\
\hline Lodos Ativados convencional & 411,7 & 1240 & 398,55 \\
\hline $\begin{array}{l}\text { Lodos Ativados convencional + } \\
\text { Coagulação }\end{array}$ & 411,7 & 1240 & 39,85 \\
\hline $\begin{array}{l}\text { UASB + Filtro Biologico } \\
\text { Percolador }\end{array}$ & 327 & 4340 & 770,53 \\
\hline $\begin{array}{l}\text { UASB + Lodos Ativados } \\
\text { Convencional }\end{array}$ & 111,16 & 434 & 115,58 \\
\hline
\end{tabular}

Com base nas características de desempenho esperadas para as alternativas de tratamento do efluente sugeridas, é possível fazer uma análise que indica que os requisitos de qualidade e de eficiência para o descarte e lançamento do efluente na rede da COPASA, foram totalmente atendidos na última alternativa (Reator UASB + Lodos Ativados Convencional), aliado a isso é a opção de melhor simplicidade operacional.

\section{Conclusões}

Este trabalho buscou comparar alternativas para tratamento de efluente gerado em uma cervejaria artesanal. Com os resultados preliminares constatou-se a importância de se caracterizar o efluente gerado, uma vez que é a partir dessa caracterização que os processos de tratamento podem ser dimensionados.

Através do dimensionamento por meio de quatro concepções e do levantamento da eficiência de cada uma delas, pode-se concluir que o sistema que utiliza reator UASB seguido do Reator Aeróbio por lodos ativados, apresenta maior eficiência e menor geração de lodo.
O que torna essa opção a melhor dentre as que foram dimensionadas nesse trabalho.

\section{Referências Bibliográficas}

1. ABNT NBR 12209. Elaboração de Projetos Hidráulico-Sanitários de Estações de Tratamento de Esgotos Sanitários. 2011.

2. Andreoli, C.V.; Von Sperling, M.; Fernandes, F. Lodos de esgotos: tratamento e disposição final. Departamento de Engenharia Sanitária e Ambiental da UFMG; Departamento de Saneamento do Paraná, 2001.

3. Chernicharo, C.A.L. (2010). Principios do tratamento biológico de águas residurárias. Vol. 5. Reatores Anaeróbios. Departamento de Engenharia Sanitária e Ambiental da UFMG, 246 p.

4. Norma Técnica T. 187/5 - Copasa. Lançamento de Efluente Não Domésticos no Sistema de Esgotamento Sanitário da COPASA. 2014.

5. Von Sperling, M. Introdução à qualidade das águas e ao tratamento de esgotos. 4ed. Minas Gerais: Departamento de Engenharia Sanitário e Ambiental UFMG, 2014.

6. Von Sperling, M. Lodos Ativados. 2ed. Minas Gerais: Departamento de Engenharia Sanitário e Ambiental UFMG, 2002.

\section{Carolina M. Rocha*, Karina S. C. Machado, Laura H. de Andrade \& Emanuel M. F. Brandt}

Pontifícia Universidade Católica de Minas Gerais, Belo Horizonte, Minas Gerais.

*E-mail:carolina.cornelio@uol.com.br. 